\title{
Changes in global potential vegetation distributions from 1911 to 2000 as simulated by the Comprehensive Sequential Classification System approach
}

\author{
LIANG TianGang $^{1 *}$, FENG QiSheng ${ }^{1}$, CAO JianJun ${ }^{2,3}$, XIE HongJie $^{4}$, LIN HuiLong $^{1}$, \\ ZHAO Jun ${ }^{5} \&$ REN JiZhou ${ }^{1}$ \\ ${ }^{1}$ State Key Laboratory of Grassland Agro-ecosystems, College of Pastoral Agriculture Science and Technology, Lanzhou University, Lanzhou \\ 730020, China; \\ ${ }^{2}$ State Key Laboratory for Information Engineering in Surveying, Mapping and Remote Sensing, Wuhan University, Wuhan 430079, China; \\ ${ }^{3}$ Basic Geographic Information Center of Gansu Province, Lanzhou 730000, China; \\ ${ }^{4}$ University of Texas at San Antonio, Department of Geological Sciences, Laboratory for Remote Sensing and Geoinformatics, San Antonio, Texas \\ 78249, USA; \\ ${ }^{5}$ College of Geography and Environmental Science, Northwest Normal University, Lanzhou 730070, China
}

Received July 18, 2011; accepted September 30, 2011; published online December 21, 2011

\begin{abstract}
Vegetation classification models play an important role in studying the response of the terrestrial ecosystem to global climate change. In this paper, we study changes in global Potential Natural Vegetation (PNV) distributions using the Comprehensive Sequential Classification System (CSCS) approach, a technique that combines geographic information systems. Results indicate that on a global scale there are good agreements among maps produced by the CSCS method and the globally well-accepted Holdridge Life Zone (HLZ) and BIOME4 PNV models. The potential vegetation simulated by the CSCS approach has 6 major latitudinal zones in the northern hemisphere and 2 in the southern hemisphere. In mountainous areas it has obvious altitudinal distribution characteristics due to topographic effects. The distribution extent for different PNV classes at various periods has different characteristics. It had a decreasing trend for the tundra and alpine steppe, desert, sub-tropical forest and tropical forest categories, and an increasing trend for the temperate forest and grassland vegetation categories. The simulation of global CSCS-based PNV classes helps to understand climate-vegetation relationships and reveals the dynamics of potential vegetation distributions induced by global changes. Compared with existing statistical and equilibrium models, the CSCS approach provides similar mapping results for global PNV and has the advantage of improved simulation of grassland classes.
\end{abstract}

potential natural vegetation, spatial distribution, biogeography model, CSCS approach

Citation: $\quad$ Liang T G, Feng Q S, Cao J J, et al. Changes in global potential vegetation distributions from 1911 to 2000 as simulated by the Comprehensive Sequential Classification System approach. Chin Sci Bull, 2012, 57: 1298-1310, doi: 10.1007/s11434-011-4870-8

Global climate and environmental changes brought about by anthropogenic means and their potentially serious impact on global and local ecosystems are receiving enormous attention from scientists, governments and society in general [1]. The study of Potential Natural Vegetation (PNV) has been proposed as a way to examine the impact of climate changes on vegetation distributions $[2,3]$. To understand the spatial

*Corresponding author (email: tgliang@1zu.edu.cn) distribution patterns of PNV and their spatial and temporal repeatability is therefore a starting point for studying climate-vegetation relationships.

The separation of anthropogenic and non-anthropogenic influences on climate-vegetation relationships is complicated. Climate-vegetation classification or relationship studies, based on existing patterns of vegetation, can potentially enable the evaluation of societal impacts on relationships between climate and vegetation. Potential vegetation 
refers to the most stable and mature climax vegetation possible without human interference, and shows the overall trend in regional vegetation development over a certain period. The study of potential vegetation can therefore reflect the influence of climatic conditions on vegetation change $[4,5]$. For this reason, potential natural vegetation has received much attention in the fields of geography, botany, climatology, and ecology [1], since the concept was proposed in 1956 [2].

In general, potential vegetation research can be divided into two stages: the first stage is a traditional qualitative investigation that is primarily based on experienced observations, and the second stage is a quantitative examination based on PNV forecast models. Quantitative methods utilizing GIS and RS techniques have generally superseded qualitative approaches for potential vegetation mapping, thereby overcoming the obstacles of subjectivity, repeatability, low efficiency, high cost and consumption of time. The simulation procedures and resulting outputs of such quantitative methods depend strongly on digitization and visualization techniques. Simulations result in two types of vegetation classification models: one consists of statistical models based on biogeographical and plant physiology parameters [6,7] and the other is process-based [8-11]. The latter has particularly improved our ability to understand the response of terrestrial vegetation to past and future environmental variations at global-to-regional scales [1]. However, a process-based model tends to require the integration of more parameters and a great deal of data to adequately consider biogeographical and biogeochemical processes and fully simulate the dynamics of the terrestrial ecosystem (often a shortcoming for the models). There has been little investigation into the level of complexity that is required to capture primary climate-vegetation feedbacks, despite the fact that increasing complexity is raising the computational costs of vegetation classification simulations [12,13]. Additionally, process-based models can have difficulty simulating climate-vegetation relationships from the more distant past, because of the limited availability of historical observations in many parts of the world. This increases the likelihood of errors in plant-types prediction for past time periods [13]. In comparison with process-based models, biogeographic models, which depend on climatic observation data collected over a broad geographical extent and a long time span, are characterized by simple input parameters [11]. In a related field, plant ecologists have been interested in understanding the geographic distribution of vegetation and the consequences of climate change to vegetation dynamics. This aspect has made the biogeographic approach, in which the distribution of vegetation types is predicted from climate variables, more popular [2]. Thus, biogeographic models have an irreplaceable role in the study of the dynamics of potential vegetation distribution on a global scale.

In order to explore the global terrestrial vegetation classes and their areal extent, a natural vegetation classification approach, the Comprehensive Sequential Classification System (CSCS) [14], is used in this study. The CSCS approach is a biogeographic simulation method that was used originally to classify grasslands in China [15]. Using this approach, global potential vegetation is divided into 42 classes based on a biogeographic model; additional detailed grassland vegetation types can be added, which makes this approach significantly different from most other potential vegetation classification methods. This paper documents the first application of the CSCS approach on a global scale, and provides a scientific basis for the temporal and spatial distribution of potential terrestrial vegetation, with a focus on grassland vegetation. The purposes of this study are (1) to validate the CSCS-derived model at a global scale by comparing it with the Holdridge Life Zone (HLZ) and BIOME4 PNV classification models; (2) to examine the spatial distribution characteristics of global potential vegetation in 2000 as generated by the CSCS method; and (3) to analyze the changes in the global potential vegetation distribution over a 30-year temporal scale during the 90 years from 1911 to 2000, based on the CSCS method applied to broad vegetation categories.

\section{Materials and methods}

\subsection{The CSCS approach for mapping potential natural vegetation}

The CSCS approach is formulated through the grouping or clustering of units with similar moisture and temperature properties [14]. CSCS consists of a 3-class level: Class, Subclass and Type. At the first level, vegetation is grouped into classes according to an index of moisture and temperature. At the second level, vegetation subclasses are differentiated by edaphic conditions. At the third level, vegetation types within a subclass are distinguished by vegetation characteristics.

The class level is the basic unit, and it is identified according to zonal characteristics of biological climate. In practice, the class is determined by combining the quantitative biological climate indices of average annual cumulative temperature above $0^{\circ} \mathrm{C}(\Sigma \theta)$ (i.e., Growing Degree-Days on $0^{\circ} \mathrm{C}$ base, GDD0) and humidity $(K)$, as calculated by [16].

$$
K=\mathrm{MAP} /(0.1 \times \Sigma \theta)=\mathrm{MAP} /(0.1 \times \mathrm{GDD} 0),
$$

where MAP is the annual mean precipitation (mm); and 0.1 is a justified coefficient of the model.

Based on decades of studies [14-19], 7 thermal zones and 6 humidity zones (Figure 1) have been identified and used to differentiate vegetation classes. The CSCS recognizes 42 vegetation classes (Table 1 ), of which all but the tropical desert class (class code 7 of Table 1) are present in China [14]. To more explicitly reflect the spatial distribution of potential vegetation at a large scale, classes are merged into 10 broad vegetation categories (Table 2 ). 
Table 1 The PNV classes recognized by the CSCS approach

\begin{tabular}{|c|c|c|c|c|}
\hline Class-ID & Code & Thermal grade & Humidity & Class name \\
\hline IA1 & 1 & frigid & extrarid & frigid desert, alpine desert \\
\hline IIA2 & 2 & cold temperate & extrarid & montane desert \\
\hline IIIA3 & 3 & cool temperate & extrarid & temperate desert \\
\hline IVA4 & 4 & warm temperate & extrarid & warm temperate desert \\
\hline VA5 & 5 & warm & extrarid & subtropical desert i \\
\hline VIA6 & 6 & subtropical & extrarid & subtropical desert ii \\
\hline VIIA7 & 7 & tropical & extrarid & tropical desert \\
\hline IB8 & 8 & frigid & arid & frigid semidesert, alpine semidesert \\
\hline IIB9 & 9 & cold temperate & arid & montane semidesert \\
\hline IIIB10 & 10 & cool temperate & arid & temperate semidesert \\
\hline IVB11 & 11 & warm temperate & arid & warm temperate semidesert \\
\hline VB12 & 12 & warm & arid & subtropical semidesert \\
\hline VIB13 & 13 & subtropical & arid & subtropical desert brush \\
\hline VIIB14 & 14 & tropical & arid & tropical desert brush \\
\hline IC15 & 15 & frigid & semiarid & dry tundra, alpine steppe \\
\hline IIC16 & 16 & cold temperate & semiarid & montane steppe \\
\hline IIIC17 & 17 & cool temperate & semiarid & temperate typical steppe \\
\hline IVC18 & 18 & warm temperate & semiarid & warm temperate typical steppe \\
\hline VC19 & 19 & warm & semiarid & subtropical grasses-fruticous steppe \\
\hline VIC20 & 20 & subtropical & semiarid & subtropical brush steppe \\
\hline VIIC21 & 21 & tropical & semiarid & savanna \\
\hline ID22 & 22 & frigid & subhumid & moist tundra, alpine meadow steppe \\
\hline IID23 & 23 & cold temperate & subhumid & montane meadow steppe \\
\hline IIID24 & 24 & cool temperate & subhumid & meadow steppe \\
\hline IVD25 & 25 & warm temperate & subhumid & forest steppe \\
\hline VD26 & 26 & warm & subhumid & deciduous broad leaved forest $\mathrm{i}$ \\
\hline VID27 & 27 & subtropical & subhumid & sclerophyllous forest \\
\hline VIID28 & 28 & tropical & subhumid & xerophytic forest \\
\hline IE29 & 29 & frigid & humid & tundra, alpine meadow \\
\hline IIE30 & 30 & cold temperate & humid & montane meadow \\
\hline IIIE31 & 31 & cool temperate & humid & forest steppe, deciduous broad leaved forest \\
\hline IVE32 & 32 & warm temperate & humid & deciduous broad leaved forest ii \\
\hline VE33 & 33 & warm & humid & evergreen deciduous broad leaved forest \\
\hline VIE34 & 34 & subtropical & humid & evergreen broad leaved forest $\mathrm{i}$ \\
\hline VIIE35 & 35 & tropical & humid & seasonal rain forest \\
\hline IF36 & 36 & frigid & perhumid & rain tundra, alpine meadow \\
\hline IIF37 & 37 & cold temperate & perhumid & perhumid taiga forest \\
\hline IIIF38 & 38 & cool temperate & perhumid & mixed coniferous broad leaved forest \\
\hline IVF39 & 39 & warm temperate & perhumid & deciduous broad leaved forest iii \\
\hline VF40 & 40 & warm & perhumid & deciduous-evergreen broad leaved forest \\
\hline VIF41 & 41 & subtropical & perhumid & evergreen broad leaved forest ii \\
\hline VIIF42 & 42 & tropical & perhumid & rain forest \\
\hline
\end{tabular}

Table 2 Relationships between broad vegetation categories and classes according to CSCS

\begin{tabular}{ccccc}
\hline Code & $>0$ Annual cumulative temperature (GDD0) & Humidity $(\mathrm{K})$ & Broad vegetation name & Corresponding class code \\
\hline 1 & $0-1300$ & $>0$ & tundra and alpine steppe & $1,8,15,22,29,36$ \\
2 & $1300-5300$ & $0-0.3$ & frigid desert & $2,3,4$ \\
3 & $1300-6200$ & $0.3-0.9$ & semi-desert & $9,10,11,12$ \\
4 & $1300-6200$ & $0.9-1.2$ & steppe & $16,17,18,19$ \\
5 & $1300-3700$ & $1.2-2.0$ & temperate humid grassland & $23,24,30$ \\
6 & $1300-5300$ & $>1.2$ & temperate forest & $25,31,32,37,38,39$ \\
7 & $5300-8000$ & $>1.2$ & sub-tropical forest & $26,27,33,34,40,41$ \\
8 & $>8000$ & $>1.5$ & tropical forest & $28,35,42$ \\
9 & $>5300$ & $0-0.3$ & warm desert & $5,6,7$ \\
10 & $>6200$ & $0.3-1.5$ & savanna & $13,14,20,21$ \\
\hline
\end{tabular}




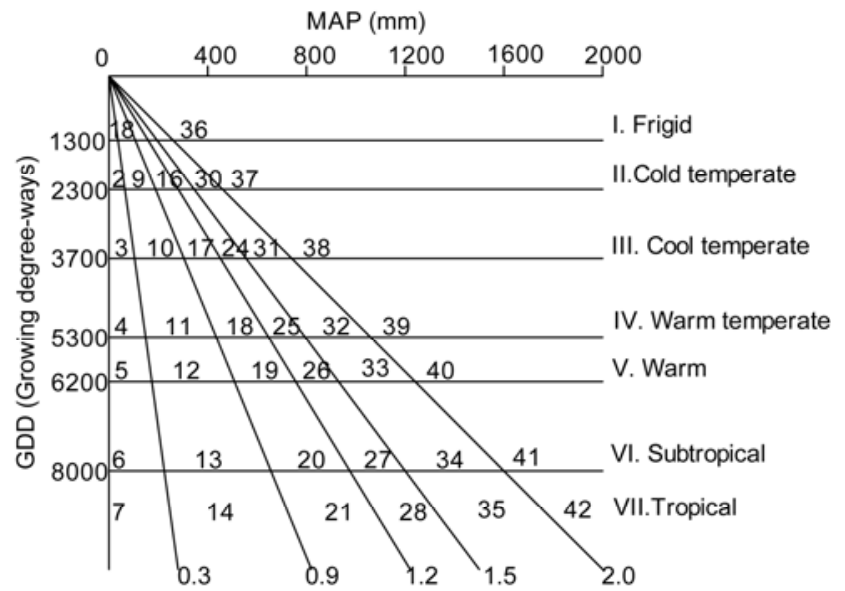

A. Extrarid B. Arid C. Semiarid D. Subhumid E. Humid F. Perhumid $K=\mathrm{MAP} / 0.1 \times \mathrm{GDD} 0$

Figure 1 Index chart for potential vegetation class (refer to Table 1) in the CSCS-derived model [14].

\subsection{Global climatic data}

Two sources of monthly precipitation and mean temperature data with different spatial resolutions for global land areas (excluding Antarctica) were used in this study to produce CSCS-based global potential vegetation distribution maps. The first was the global monthly precipitation and mean temperature dataset gridded at a 30 arc-second (i.e., about 1 $\mathrm{km})$ spatial resolution over the 50 years from 1950 to 2000 . This was generated using the thin-plate smoothing spline algorithm implemented in the ANUSPLIN software package [20] using weather stations from a large number of global, regional, national, and local sources [21]. We chose this dataset because the method that created it has been used in other global studies [22,23] and performed well in comparative tests of multiple interpolation techniques [21,24]. The other source of data was the Climate Research Unit (CRU) global climate dataset of CRU_TS 2.1 [25]. It consists of multi-variate mean monthly climatology records at $0.5^{\circ}$ resolution for global land areas (excluding Antarctica) for the period 1901-2000. In this study, the monthly precipitation and mean temperature datasets for each decade were used. To compare the agreement between the CSCS and HLZ PNV maps and simulate the change of global potential vegetation distribution using the CSCS approach, the average annual GDD0 and precipitation grid data for different periods using the two datasets were generated using ArcGIS software.

\subsection{Global DEM and continent boundary data}

The global digital elevation model at a 30 arc-second spatial resolution [21], based on the Shuttle Radar Topography Mission (STRM) dataset, was downloaded from http://srtm. csi.cgiar.org. To analyze the areas of different vegetation types, the boundary databases of Europe, Asia, Africa, the
Americas and Oceania were downloaded from http://www. diva-bgis.org/Data, and utilized in this study. Using ArcGIS software, all of the related databases are transformed to the Mollweide projection with the WGS_1984 spheroid to calculate the area of each vegetation class.

\subsection{Comparative maps of global potential vegetation}

HLZ is a model that formulates the distribution of potential terrestrial ecosystems in terms of biotemperature, precipitation and potential evapotranspiration [26]. It relates the distribution of major ecosystems (termed "life zones") to the bioclimatic variables. The HLZ classification divides the world into over 38 life zones (Table 3 ) on the basis of mean annual biotemperature (in ${ }^{\circ} \mathrm{C}$ ), average total annual precipitation (in $\mathrm{mm}$ ) and potential evapotranspiration ratio (PER) logarithmically $[6,26,27]$. BIOME4 is a process-based equilibrium, biogeographically- and biogeochemically-coupled vegetation model, modified from Biome3 [28], which simulates global vegetation in the form of 13 plant functional types (PFTs) that are combined to form 28 biomes (Table 3 ) [29-31]. BIOME4 has been employed in a number of studies of past, present and potential future vegetation patterns [1,32-34].

To study changes in the potential vegetation distribution and make direct comparisons between the CSCS-derived and other well-known global PNV maps (e.g., HLZ, BIOME4), the following PNV maps were used or created by ArcGIS software. First, to demonstrate the accuracy of CSCS PNV map and make appropriate comparisons over the same time period, the CSCS and HLZ PNV maps used in this study were created for 1961-1990 using global mean annual climatology data from the CRU_TS 2.1 dataset, and an existing global BIOME4 PNV map covering the same time period for global mean annual climatology data [29-31]. Consideration of the big differences between the CSCS, HLZ and BIOME4 models in terms of classification indices, threshold values, classification approaches, etc. is required in order to make direct comparisons (i.e., CSCS vs. HLZ, CSCS vs. BIOME4 and HLZ vs. BIOME4) of the three vegetation models; some merging of categories is required. Through repeated tests, a reclassification into five broad categories was proposed; i.e., the 10 categories of CSCS, 38 categories of HLZ, and 28 categories of BIOME4 were divided into the same 5 broad categories, so that systematic comparisons and analyses of the three models would be possible. The five reclassified broad vegetation categories are tundra, desert, boreal and temperate forest, sub-tropical and tropical forest, and grasslands (Table 4). We found that it was not possible to divide the boreal and temperate forest class into boreal forest, temperate forest, sub-tropical forest and tropical forest, since there is also no way to find the same subclasses in the HLZ and MOME4 models. The HLZ model divides forest into boreal forest, cool temperate forest, warm temperate forest, subtropical 
Table 3 Global PNV types in the HLZ and BIOME4 models

\begin{tabular}{cl}
\hline Classification system & PNV type name and code \\
\hline HLZ & Polar desert(1), subpolar dry tundra(2), subpolar moist tundra(3), subpolar wet tundra(4), subpolar rain tundra(5), boreal \\
& desert(6), boreal dry scrub(7), boreal moist forest(8), boreal wet forest(9), boreal rain forest(10), cool temperate desert(11), \\
& cool temperate desert scrub(12), cool temperate steppe(13), cool temperate moist forest(14), cool temperate wet forest(15), \\
& cool temperate rain forest(16), warm temperate desert(17), warm temperate desert scrub(18), warm temperate thorn \\
& scrub(19), warm temperate dry forest(20), warm temperate moist forest(21), warm temperate wet forest(22), warm temper- \\
& ate rain forest(23), subtropical desert(24), subtropical desert scrub(25), subtropical thorn woodland(26), subtropical dry \\
& forest(27), subtropical moist forest(28), subtropical wet forest(29), subtropical rain forest(30), tropical desert(31), tropical \\
& desert scrub(32), tropical thorn woodland(33), tropical very dry forest(34), tropical dry forest(35), tropical moist forest(36), \\
& tropical wet forest(37), tropical rain forest(38) \\
& Tropical evergreen forest(1), tropical semi-deciduous forest(2), tropical deciduous forest/woodland(3), temperate decidu- \\
& ous forest(4), temperate conifer forest(5), warm mixed forest(6), cool mixed forest(7), cool conifer forest(8), cold mixed \\
& forest(9), evegreen taiga/montane forest(10), deciduous taiga/montane forest(11), tropical savanna(12), tropical xerophytic \\
& shrubland(13), temperate xerophytic shrubland(14), temperate sclerophyll woodland(15), temperate broadleaved savan- \\
& na(16), open conifer woodland(17), boreal parkland(18), tropical grassland(19), temperate grassland(20), desert(21), steppe \\
& tundra(22), shrub tundra(23), dwarf shrub tundra(24), prostrate shrub tundra(25), cushion-forb, lichen and moss(26), bar- \\
& ren(27), land ice(28) \\
\hline &
\end{tabular}

Table 4 Broad vegetation categories reclassified by the CSCS, HLZ and BIOME4 PNV types

\begin{tabular}{cccc}
\hline Category name & $\begin{array}{c}\text { Broad vegetation } \text { code }^{\text {a) }} \text { in the } \\
\text { CSCS }\end{array}$ & $\begin{array}{c}\text { Vegetation type code }^{\text {b) }} \text { in the } \\
\text { HLZ }\end{array}$ & $\begin{array}{c}\text { Vegetation type code }^{\text {b) }} \text { in the } \\
\text { BIOME4 }\end{array}$ \\
\hline Tundra & 1 & $1,2,3,4,5$ & $22,23,24,25,26,28$ \\
Desert & $2,3,9$ & $6,7,11,12,17,18,19,24,25$, & 21,27 \\
Boreal and temperate forest & 6 & 31,32 & $4,5,7,8,9,10,11,15,17$ \\
Sub-tropical and tropical forest & 7,8 & $8,9,10,14,15,16$ & $1,2,3,6$ \\
Grassland & $4,5,10$ & $33,34,35,36,37,38$ & $13,13,14,16,18,19,20$ \\
\hline
\end{tabular}

a) Broad vegetation name in the CSCS model refers to Table 2. b) The vegetation type name refers to Table 3 .

forest and tropical forest, whereas BIOME4 divides it into only two subclasses of temperate forest and tropical forest. Second, to study the changes of global potential vegetation distribution in space at a $0.5^{\circ}$ resolution in latitude and longitude, as well as in time for 30-year periods from 1911 to 2000, three CSCS PNV maps for the periods 1911-1940 (T1), 1941-1970 (T2) and 1971-2000 (T3) were created from the global CRU_TS 2.1 datasets. Third, to reflect the detailed spatial distribution characteristics at the most recent time (i.e., year 2000), a global CSCS PNV map was created using the 30 arc-second high spatial resolution datasets from 1950 to $2000[20,21]$. To calculate the area of each PNV class in the global CSCS PNV map, water, and permanent snow and ice cover were excluded using the MODIS IGBP land cover classification dataset from 2001, sourced from http://wist.echo.nasa.gov.

\subsection{The KAPPA statistic for PNV map comparisons}

The Kappa statistic is widely used in assessing model-simulated vegetation distributions. The advantage of the Kappa statistic is that it takes chance agreement into account, regardless of the number of categories being compared in the maps $[1,8]$. In this study, the Kappa statistic was used to evaluate the similarities between the two kinds of PNV maps. For each category, $i$ is the constructed error matrix for two compared PNV maps, the Kappa statistic is calculated by the following equation:

$$
K_{i}=\frac{\left(p_{i i}-p_{i, \text { row }} p_{\mathrm{col}, j}\right)}{\left(\left(p_{i, \text { row }}+p_{\mathrm{col}, j}\right) / 2-p_{i, \text { row }} p_{\mathrm{col}, j}\right)},
$$

where $p_{i \text {, row }}$ is the row total for each category $i ; p_{\mathrm{col}, j}$ is the column total for each category $i$; and $p_{i i}$ is the individual entry for the row and column on the main diagonal of constructed error matrix. The overall agreement between two compared maps is estimated by the formula:

$$
K=\left(p_{0}-p_{e}\right) /\left(1-p_{e}\right),
$$

where $p_{0}=\sum_{i=1}^{c} p_{i j} ; p_{e}=\sum_{i=1}^{c} p_{i, \mathrm{row}} p_{\mathrm{col}, j} ; \quad$ and $c$ is the number of categories in each data set.

In general, Kappa statistics greater than 0.85 are considered excellent, values $0.7-0.85$ are very good, values $0.55-0.7$ are good, values $0.4-0.55$ are fair, and values below 0.4 are considered poor or very poor [28].

\section{Results}

\subsection{Agreement in CSCS, HLZ and BIOME4 PNV maps}

From Table 5, it can be seen that the CSCS and HLZ PNV maps are more in agreement than comparisons of maps 
Table 5 The Kappa statistics for the 5 broad PNV categories identified by CSCS, HLZ and BIOME4 maps for the period 1961-1990 at a global scale

\begin{tabular}{ccccccc}
\hline \multirow{2}{*}{ Category name } & \multicolumn{5}{c}{ Broad vegetation category } \\
\cline { 2 - 7 } & Tundra & Desert & Boreal \& temperate forest & Sub-tropical \& tropical forest & Grassland & Overall \\
\hline CSCS vs. HLZ & 0.90 & 0.92 & 0.78 & 0.64 & 0.26 & 0.74 \\
CSCS vs. BIOME4 & 0.76 & 0.67 & 0.62 & 0.68 & 0.42 & 0.63 \\
HLZ vs. BIOME4 & 0.84 & 0.68 & 0.72 & 0.60 & 0.14 & 0.62 \\
\hline
\end{tabular}

from CSCS and BIOME4 or HLZ and BIOME4. The agreement between the CSCS and BIOME4 PNV maps (overall Kappa statistics of 0.63 ) is similar to that of the HLZ and BIOME4 PNV maps (overall Kappa statistics of 0.62), both notably less than the very good agreement between CSCS and HLZ PNV maps (overall Kappa statistics of 0.74). Good agreement also occurs for CSCS vs. BIOME4 and HLZ vs. BIOME4 PNV maps with a $0.5^{\circ}$ block size simulated by CSCS, HLZ and BIOME4 models using global climatology datasets collected over the same time period (e.g., the 30 years from 1961 to 1990).

In the 5 broad vegetation categories, the tundra has an excellent agreement (0.90) between CSCS vs. HLZ maps, and very good agreements $(0.76$ and 0.84$)$ between CSCS vs. BIOME4 and HLZ vs. BIOME4 maps. A similar result is found for the desert, where the Kappa statistics vary from 0.67 to 0.92 . The predicted extents of the boreal and temperate forest show very good agreements $(0.78$ and 0.72$)$ under CSCS vs. HLZ and HLZ vs. BIOME4 comparisons and good agreement (0.62) for the CSCS vs. BIOME4 comparison. For sub-tropical and tropical forests, there are good agreements among the three PNV maps, with the Kappa statistics varying from 0.60 to 0.68 . The grassland category has only fair agreement (0.42) for the CSCS vs.
BIOME4 comparison, and very poor agreements (0.26 and 0.14) for CSCS vs. HLZ and HLZ vs. BIOME4 comparisons.

\subsection{Spatial distribution characteristics of PNV in year 2000}

From Figure 3, 10 broad vegetation categories and 42 classes of the potential vegetation can be identified for the world excluding Antarctica. Statistical analysis indicates that the area of global potential vegetation, excluding regions of permanent snow and ice cover, is $1.289335 \times 10^{8}$ $\mathrm{km}^{2}$, which covers $96.07 \%$ of the total land area of Earth (Table 6).

The spatial distributions of classes of potential vegetation are significantly different from region to region. In Asia, the potential vegetation area is about $4.29036 \times 10^{7} \mathrm{~km}^{2}$, which is the most extensive of the 5 continental regions and covers $33.28 \%$ of the total area of global potential vegetation excluding Antarctica (Table 6). Because of its extent and complicated ecological environment, Asia has the greatest number of vegetation categories in comparison to the other continental regions. Based on the CSCS classification approach (Table 1 ), there are 42 potential vegetation

Table 6 Statistical result of global CSCS PNV broad categories

\begin{tabular}{|c|c|c|c|c|c|c|c|c|c|c|c|}
\hline \multirow{2}{*}{ Extent } & \multirow{2}{*}{ Indicator } & \multicolumn{10}{|c|}{ Broad vegetation category code ${ }^{\text {a) }}$} \\
\hline & & 1 & 2 & 3 & 4 & 5 & 6 & 7 & 8 & 9 & 10 \\
\hline \multirow[t]{2}{*}{ Globe } & $\operatorname{Area}\left(10^{4} \mathrm{~km}^{2}\right)$ & 1398.83 & 207.52 & 773.78 & 378.10 & 710.41 & 2407.96 & 989.25 & 1809.23 & 1893.66 & 2324.61 \\
\hline & Globe $(\%)^{\mathrm{b})}$ & 10.85 & 1.61 & 6.00 & 2.93 & 5.51 & 18.68 & 7.67 & 14.03 & 14.69 & 18.03 \\
\hline \multirow[t]{2}{*}{ Asia } & Area $\left(10^{4} \mathrm{~km}^{2}\right)$ & 825.38 & 185.76 & 404.61 & 154.75 & 325.02 & 825.25 & 294.97 & 430.66 & 520.78 & 323.18 \\
\hline & Globe $(\%)^{\mathrm{c})}$ & 59.00 & 89.51 & 52.29 & 40.93 & 45.75 & 34.27 & 29.82 & 23.80 & 27.50 & 13.90 \\
\hline \multirow[t]{2}{*}{ Europe } & Area $\left(10^{4} \mathrm{~km}^{2}\right)$ & 67.04 & 0.02 & 38.28 & 70.19 & 174.99 & 658.45 & 13.97 & 1.52 & 0.30 & 10.66 \\
\hline & Globe $(\%)^{\mathrm{c}}$ & 4.79 & 0.01 & 4.95 & 18.56 & 24.63 & 27.34 & 1.41 & 0.08 & 0.02 & 0.46 \\
\hline \multirow[t]{2}{*}{ Africa } & Area $\left(10^{4} \mathrm{~km}^{2}\right)$ & 0.02 & 0.77 & 57.80 & 18.89 & 0.92 & 21.53 & 252.08 & 438.52 & 1118.29 & 1061.26 \\
\hline & Globe $(\%)^{c)}$ & 0.00 & 0.37 & 7.47 & 5.00 & 0.13 & 0.89 & 25.48 & 24.24 & 59.05 & 45.65 \\
\hline \multirow[t]{2}{*}{ America } & Area $\left(10^{4} \mathrm{~km}^{2}\right)$ & 506.13 & 20.97 & 224.51 & 121.66 & 208.39 & 846.83 & 402.23 & 923.83 & 60.61 & 481.70 \\
\hline & Globe $(\%)^{\mathrm{c})}$ & 36.18 & 10.10 & 29.02 & 32.18 & 29.33 & 35.17 & 40.66 & 51.06 & 3.20 & 20.72 \\
\hline \multirow[t]{2}{*}{ Oceania } & Area $\left(10^{4} \mathrm{~km}^{2}\right)$ & 0.27 & 0.00 & 48.59 & 12.60 & 1.09 & 55.90 & 25.99 & 14.71 & 193.68 & 447.81 \\
\hline & Globe $(\%)^{c}$ & 0.02 & 0.00 & 6.28 & 3.33 & 0.15 & 2.32 & 2.63 & 0.81 & 10.23 & 19.26 \\
\hline
\end{tabular}

a) The numbers from 1 to 10 correspond to the broad vegetation categories: 1, tundra and alpine steppe; 2 , frigid desert; 3 , semi-desert; 4 , steppe; 5, temperate humid grassland; 6, temperate forest; 7, sub-tropical forest; 8, tropical forest; 9, warm desert; 10, savanna. b) The percentage of the Earth's land surface covered by the vegetation category. c) The percentage of the global distribution of the vegetation category found in the continent or region. 

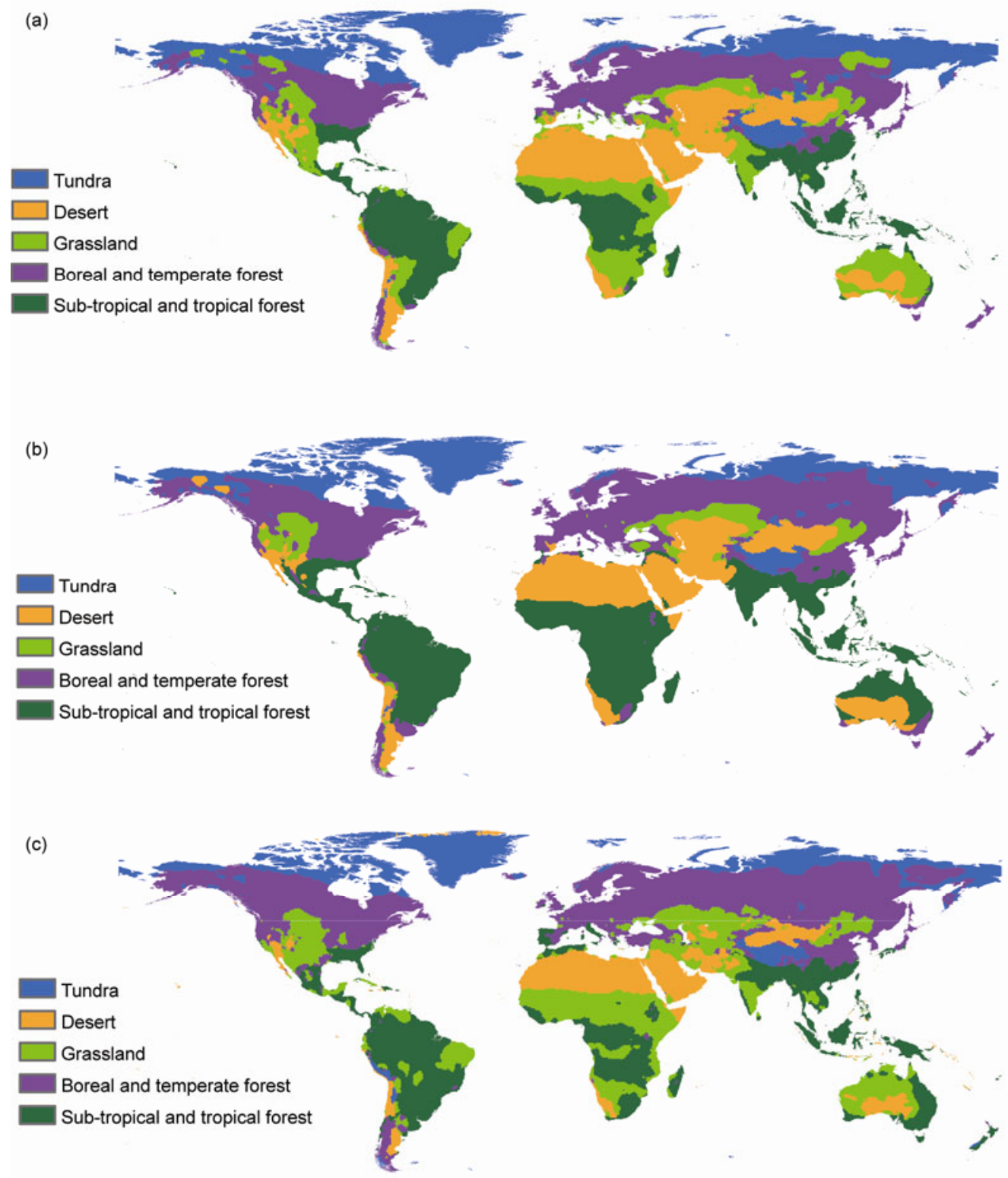

Figure 2 The CSCS (a), HLZ (b) and BIOME4 (c) PNV maps simulated by 30-year (1961-1990) global climatology grid data at $0.5^{\circ}$ spatial resolution.

classes in Asia. Of these, 16 account for over 50\% of each corresponding global area. The top 6 classes found in Asia account for over $80 \%$ of their corresponding global extent. They are temperate desert (3), warm temperate desert (4), frigid semidesert and alpine semidesert (8), dry tundra and alpine steppe (15), moist tundra and alpine meadow steppe (22), and montane meadow steppe (23).

The Americas form the second largest region and they contain 42 potential vegetation classes. The potential vegetation area is $3.79686 \times 10^{7} \mathrm{~km}^{2}$, which covers $29.45 \%$ of the total area of the global potential vegetation. The dominant vegetation classes are deciduous broad leaved forest iii (39) and rain forest (42), with their individual areas accounting for over 50\% of each corresponding global area.

Africa and Oceania have potential vegetation areas of $2.97008 \times 10^{7}$ and $8.0064 \times 10^{6} \mathrm{~km}^{2}$, or $23.04 \%$ and $6.21 \%$ of the total global potential vegetation area, respectively. The dominant vegetation classes include tropical desert (7), tropical desert brush (14), seasonal rain forest (35) on the African continent, and rain tundra and alpine meadow (36), perhumid taiga forest (37), and rain forest (42) in Oceania.

Europe has a potential vegetation area of $1.03542 \times 10^{7}$ $\mathrm{km}^{2}$, including 24 potential vegetation classes, and covers $8.03 \%$ of the total global potential vegetation. The dominant vegetation classes are forest steppe (25), deciduous broad leaved forest (31), perhumid taiga forest (37) and mixed 


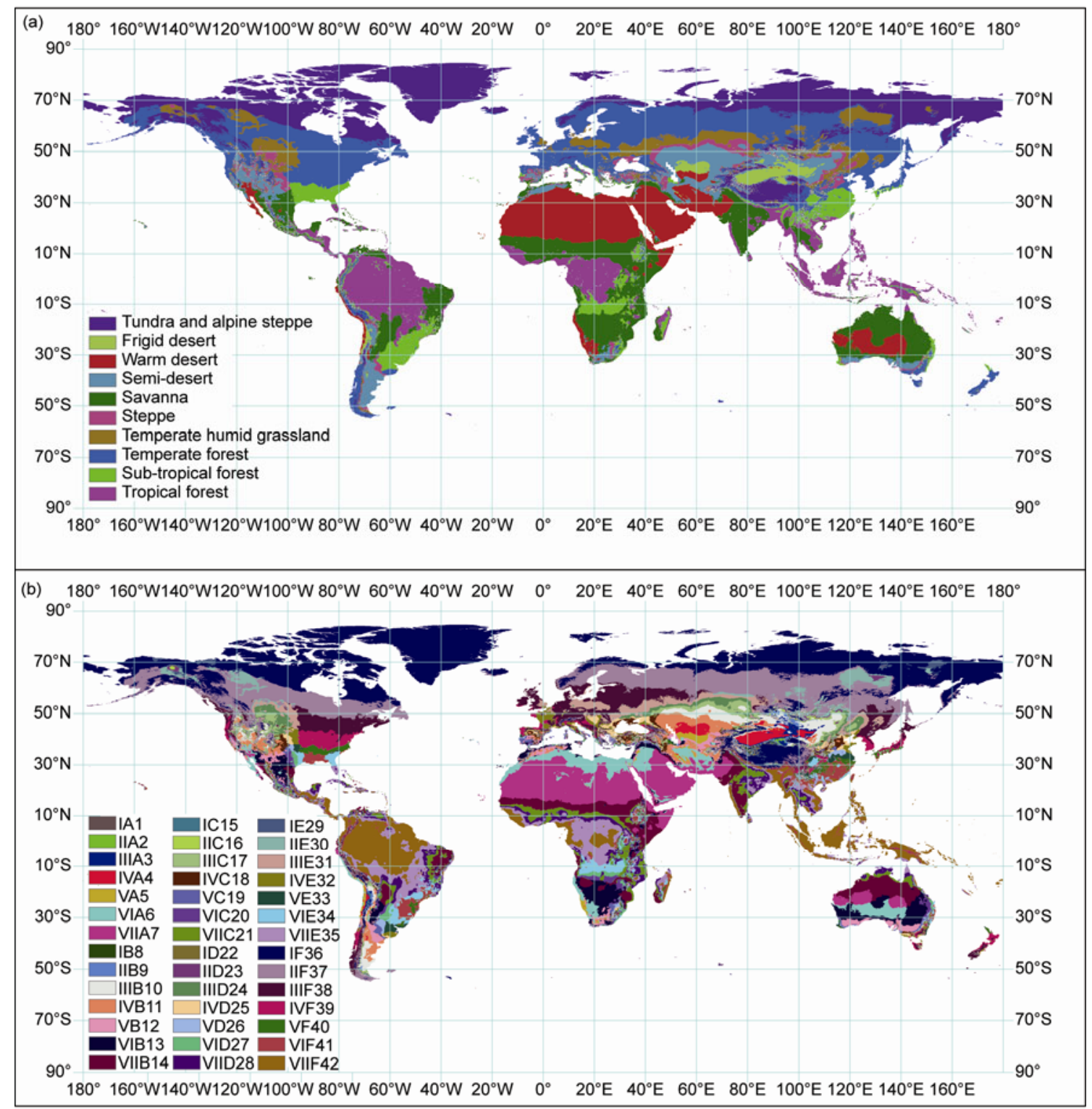

Figure 3 The spatial distribution of the 10 broad vegetation categories (a) and 42 vegetation classes (refer to Table 1) (b) in the global CSCS PNV maps in year 2000 .

coniferous broad leaved forest (38).

The potential vegetation is characterized by a significant distribution pattern in latitudinal and altitudinal directions (Figure 3). From the Equator to the North Pole, there are 6 major latitudinal zones, which in sequence are: (1) tropical forest, dominated by rain forest (code 42), mainly distributed in the north of South America, Middle Africa and southeastern Asia; (2) Savanna, dominated by tropical desert brush (14) and sub-tropical desert brush (13), mainly distributed in eastern and central Africa, Central America, and the south of southern Asia; (3) warm desert and sub-tropical forest, principally including tropical desert (7), evergreen broad leaved forest ii (41), and mainly distributed in North
Africa, North America and a large part of Asia; (4) semi-desert and frigid desert, mixed with steppe in central Eurasia and southwestern North America, as well as tundra and alpine steppe in the Tibetan Plateau, dominated by the classes of temperate semi-desert (10), warm temperate semi-desert (11), warm temperate desert (4), and rain tundra and alpine meadow (36); (5) mixture of temperate humid grassland and temperate forest, mainly including the classes of perhumid taiga forest (37), mixed coniferous broad leaved forest (38) and meadow steppe (24), and distributed over all of Eurasia, extending from the east of North America to the east coast of the Pacific Ocean; and (6) tundra and alpine steppe, dominated by the classes of rain tundra and 
alpine meadow (36) and tundra and alpine meadow (29), mainly distributed in northern North America, Greenland and most northern Eurasia.

In the southern hemisphere, from the Equator to the most southern edge of Oceania, there are just two major latitudinal zones: (1) The first is dominated by tropical forest, sub-tropical forest and savanna vegetation categories, mixed with a little bit of steppe, and warm desert. Major classes found in this zone include rain forest (42), seasonal rain forest (35), tropic desert brush (14), sub-tropic desert brush (13) and tropical desert (17). This region is mainly distributed in southern and central Africa, northern and central South America, the south of southeastern Asia, and northern Oceania. (2) The second region is dominated by temperate forest and semi-desert, mainly including the classes of perhumid taiga forest (37) and sub-tropical desert brush (13), and mainly is distributed in southern-most America, Africa and Oceania. As a result of interactions among topography, climate and vegetation, there are probably more vegetation categories distributed in eastern South America.

In mountainous areas, spatial vegetation distribution is more complicated and has obvious vertical distribution characteristics because of topographic effects. For example, in the Himalaya mountains and Tibetan plateau in southwestern China and adjacent areas (Figure 4), there is a great deal of tundra and alpine steppe (purple color) scattered with ice and snow (white color) mixed with temperate humid grassland (yellow color) and temperate forest (dark blue color) (Figure 4(a) and (b)). From the top area of Mt. Everest to the southwest through Nepal and India (Figure $4(c)$ ), the elevation decreases from $>8200 \mathrm{~m}$ to about $50 \mathrm{~m}$ (Figure 4(d)). The potential vegetation categories change stepwise from tundra and alpine steppe, to temperate forest, to sub-tropical forest (bright green) to tropical forest (red color) in the southern Nepal, and to savanna (dark green) in the north of India.

\subsection{Change in global PNV distribution from 1911 to 2000}

From Table 7, clear decreasing trends can be seen for the area of tundra and alpine steppe and desert vegetation categories. This has amounted to $6.06 \%$ and $5.90 \%$, respectively, over the 90 years from 1911 to 2000 . Over the same period, the area of forest and grassland vegetation categories has increased by $2.23 \%$ and $4.39 \%$, respectively.

In the 3 forest vegetation categories, the total area increased by $3.06 \%$ over the period from 1940 (Figure 5(a)) to 1970 (Figure $5(\mathrm{~b})$ ), then slightly decreased by $0.80 \%$ over the period from 1970 to 2000 (Figure 5(c)). The area of temperate forest increased significantly from 1940 to 1970 , but no obvious trend emerged from 1970 to 2000. The area of sub-tropical forest changed slightly in the 90 years. It had a small increase from 1940 to 1970 , which was followed by a slight decreasing trend after 1970. This is the same as what was observed for variation in tropical forest cover. In

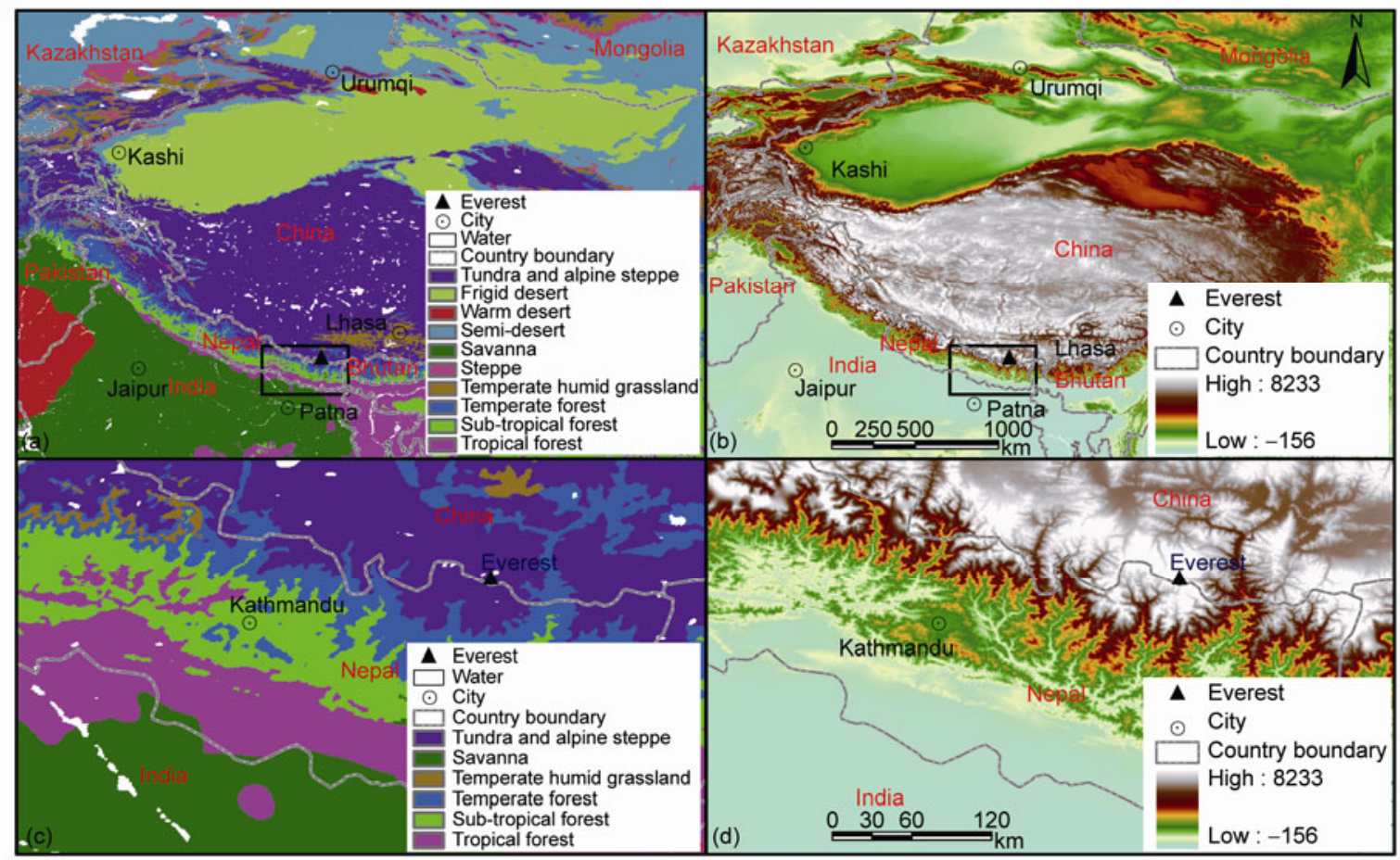

Figure 4 The spatial distribution of the CSCS PNV on vertical level in the Himalaya mountains. (a) and (b) depict the PNV map and digital elevation model in the Himalaya area; (c) and (d) are PNV map and digital elevation model in the area surrounding Everest. 
Table 7 Area variation for the 10 broad vegetation categories in the periods 1911-1940 (T1), 1941-1970 (T2) and 1971-2000 (T3)

\begin{tabular}{|c|c|c|c|c|c|c|}
\hline \multirow{2}{*}{ Broad vegetation category } & \multicolumn{3}{|c|}{ Area $\left(10^{4} \mathrm{~km}^{2}\right)$ in different periods } & \multicolumn{3}{|c|}{ Variation rate $(\%)$} \\
\hline & $\mathrm{T} 1$ & $\mathrm{~T} 2$ & T3 & T1 vs.T2 & T2 vs. T3 & T1 vs. T3 \\
\hline Tundra and alpine steppe & 1400.95 & 1363.57 & 1316.04 & -2.67 & -3.49 & -6.06 \\
\hline Frigid desert & 204.25 & 207.59 & 165.97 & 1.64 & -20.05 & -18.74 \\
\hline Semi-desert & 783.88 & 754.44 & 771.85 & -3.76 & 2.31 & -1.54 \\
\hline Steppe & 437.79 & 395.19 & 398.12 & -9.73 & 0.74 & -9.06 \\
\hline Temperate humid grassland & 489.38 & 431.56 & 444.87 & -11.82 & 3.08 & -9.10 \\
\hline Temperate forest & 2557.1 & 2691.17 & 2699 & 5.24 & 0.29 & 5.55 \\
\hline Sub-tropical forest & 911.22 & 919.65 & 903.58 & 0.93 & -1.75 & -0.84 \\
\hline Tropical forest & 2329.52 & 2364.2 & 2324.4 & 1.49 & -1.68 & -0.22 \\
\hline Warm desert & 1863.03 & 1831.54 & 1745.2 & -1.69 & -4.71 & -6.32 \\
\hline Savanna & 1896.96 & 1915.18 & 2105.06 & 0.96 & 9.91 & 10.97 \\
\hline
\end{tabular}
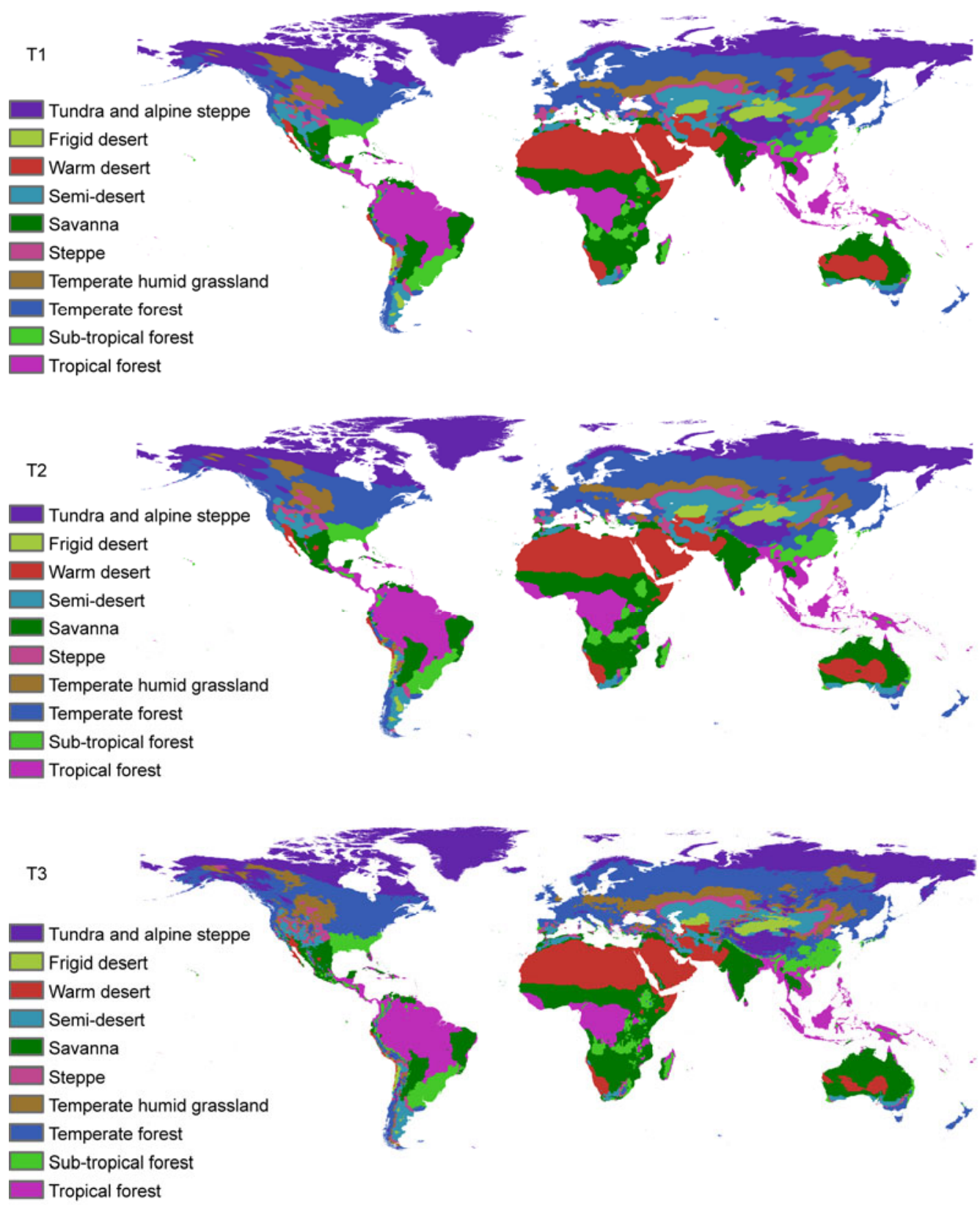

Figure 5 The geographic distribution of broad vegetation categories in the three CSCS PNV maps simulated by the CRU TS 2.1 climatic data in the periods from 1911 to 1940 (T1), 1941 to 1970 (T2) and 1971 to 2000 (T3). 
the three desert vegetation categories, the overall area had a decreasing trend, falling by $2.02 \%$ and $3.96 \%$ for the periods from 1940 to 1970 and 1970 to 2000, respectively. The semi-desert vegetation category also had an obvious decreasing trend in the period from 1940 to 1970 , but then a slight increasing trend from 1970 to 2000, but overall the trend decreased for the entire study period. For frigid desert, there was no obvious variation in the period from 1940 to 1970, whereas a significant decrease, $20.05 \%$, occurred during the period from 1970 to 2000 , the greatest change rate of the ten broad vegetation categories. The warm desert showed a decreasing trend of $6.32 \%$ for the entire period. In the three grassland vegetation categories, the area variation rate decreased by $2.91 \%$ in the period from 1940 to 1970 , then increased by $7.52 \%$ from 1970 to 2000 . As a whole, the area increased significantly for the savanna, but decreased for the steppe and temperate humid grassland vegetation categories.

\section{Discussion}

Overall, good agreement was found among the CSCS, HLZ and BIOME4 PNV maps in their evaluations of the extent of tundra, forests and desert, and poor agreement was found for grassland vegetation coverage. However, it is not an easy task to explain why. A first point to consider is that discrepancies exist in the level of detail under which grassland vegetation is classified in the three PNV models. Grassland vegetation accounts for $25 \%$ of global land coverage, but it is simplistically represented in the HLZ and BIOME4 models. In the HLZ model, 38 PNV types are recognized, but only one type of grassland (i.e., cool temperate steppe) is specified and no type of savanna [35]. The BIOME4 model focuses more on forest vegetation, including 13 types that are based on thermal grades, and evergreen, deciduous, needleleaf and mixed types from vegetation characteristics (Table 3). However, the BIOME4 model does improve over HLZ in its examination of grasslands. Of the 28 PNV types identified by BIOME4, 5 are grasslands (i.e., tropical grassland, temperate grassland, tropical savanna, cold parkland and temperate deciduous broadleaf savanna). That is, the CSCS PNV approach is even more suitable for classifying grasslands - which it was originally devised to do. Not only does it provide a detailed classification of grassland vegetation, but also produces a detailed classification of the other vegetation types. The CSCS can distinguish 42 classes of vegetation, consisting of 11 classes of grassland, 15 classes of forest, 6 classes of tundra, and 10 classes of desert (Table 1). This means that the CSCS model can produce a more balanced classification of the terrestrial ecosystem than the HLZ and BIOME4 models do. Therefore, the poorer agreements for grassland coverage as assessed by CSCS vs. HLZ and BIOME4 vs. HLZ comparisons could be primarily due to the simplification of grass- land types in the HLZ and BIOME4 models.

A second point to consider is that there are significant differences in the constraints applied in constructing the CSCS, HLZ and BIOME4 models. Both HLZ and CSCS are statistical and equilibrium models based on biologically determined climatic constraints, which consider biotemperature and precipitation (MAP) as important classification constraints. However, the model definitions are quite different. In the CSCS model, the biotemperature is defined as growing degree-days on a $0^{\circ} \mathrm{C}$ base (GDD0), and precipitation is used in the index $K(K=\mathrm{MAP} / 0.1 \times \mathrm{GDD} 0)$ [14]. However, a mean annual biotemperature is defined (i.e., the average value of mean daily temperature over $0^{\circ} \mathrm{C}$ and below $30^{\circ} \mathrm{C}, \mathrm{BT}$ ), and precipitation is not only directly used as a constraint, but generally used to simulate the potential evapotranspiration ratio (PER) (e.g., $\mathrm{PER}=58.9 \times \mathrm{BT} / \mathrm{P}$ ) as well in the HLZ system [6,26,27]. In comparison, BIOME4 is a coupled biogeographic and biogeochemical model that simulates the equilibrium distribution of major PNV types (biomes). Compared to the CSCS-derived model, the BIOME4 model employs not only more bioclimatic constraints (e.g., GDD0, GDD5, temperature of coldest month, mean monthly precipitation, temperature, and percent sunshine) but also other constraints (e.g., PFT, LAI, soil moisture) [29-31]. The above discrepancies among the CSCS, HLZ and BIOME4 models ordinarily lead to different definitions for the same vegetation type. Consequently, there are still some deviations in the definition of broad vegetation categories, even after aggregation with the original types. By repeating tests, we found that separation of the current five big categories into finer categories (e.g., the division of the forest class into boreal forest, temperate forest, sub-tropical forest and tropical forest) is difficult. This is because there are big differences in the three sets of classification indices, threshold values and classification approaches.

The Intergovernmental Panel on Climate Change (IPCC) Third Assessment Report [36,37] indicated that during the 20th century, precipitation in much of the Northern Hemisphere land areas increased by $0.2 \%$ to $1 \%$ per decade, and that no comparable systematic changes were detected in broad latitudinal averages over the Southern Hemisphere. The increase in temperature during the 20th century was the largest of any century during the past 1000 years. As a whole, global temperature had an increasing trend over the 20th century, but most of the warming occurred in the two periods from 1910 to 1945 and 1976 to 2000. Our study shows that over the entire study period, the extent of desert vegetation decreased by $5.90 \%$, and the area of grassland vegetation increased by $4.39 \%$; decreasing trends were found for the extent of sub-tropical and tropical forests, and an increasing trend for temperate forest; the tundra and alpine steppe had a decreasing trend, but more sharply decreased since the late stage of 1970s (T3). Similar results were also found at regional and global scales [1,38-42]. 
This suggests that the late 1970s may be a critical period or key starting point when the spatial distribution of potential natural vegetation started to change significantly because of obvious changes related to global climatic warming [36,37].

This study demonstrates the significant role that the CSCS approach can play in the simulation of potential vegetation distributions in relation to climate change at a global scale. This suggests that the CSCS-based models not only have the ability to investigate the effects of climate change on vegetation type and distribution, but also can contribute to balanced predictions of various vegetations, especially detailed classes of grassland vegetation. This is an obvious advantage of the CSCS-based model and a necessary supplement to the other well-known global PNV models.

\section{Conclusions}

On a global scale, there is good agreement among the CSCS, HLZ and BIOME4 PNV maps. The CSCS-derived model has the ability to successfully predict the distribution of tundra, desert and forests, and has better abilities than the HLZ classification system for the simulation of grassland. Compared to globally well-accepted PNV models like HLZ and BIOME4, the CSCS model has advantages in the simple input parameters and low computational costs. It can not only systematically classify the extent of known and unknown global terrestrial vegetation, but can recognize more detailed grassland vegetation classes as well. Additionally, a CSCS-derived model can be used to predict potential vegetation classes and their spatial distribution, which is a critical part of research regarding the effects of climate change on vegetation successions, and plays an important role in the management and planning of anthropogenic controls on terrestrial vegetation, especially in grasslands.

We thank the editor and two anonymous reviewers for helpful revisions. We especially thank Professor Kaplan who provided the global BIOME4 $P N V$ data for our research. This work was supported by the National Natural Science Foundation of China (30972135 \& 40961026) and the Cultivation Fund of the Key Scientific and Technical Innovation Project, Ministry of Education of China (708089).

1 Tang G P, Shafer S L, Bartlein P J, et al. Effects of experimental protocol on global vegetation model accuracy: A comparison of simu lated and observed vegetation patterns for Asia. Ecol Model, 2009, 220: 1481-1491

2 Zhao D S, Li S C, Wu S H. Progress on climate-vegetation modeling in the Tibetan Plateau (in Chinese). Prog Geogr, 2006, 25: 68-78

3 Poulter B, Aragaol L, Heyder U, et al. Net biome production of the Amazon Basin in the 21st century. Gl Change B, 2000, 16: 2062-2075

4 Weng E S, Zhou G S. Defining plant functional types in china for global change studies (in Chinese). Acta Phytoecol Sin, 2005, 29: 81-97

5 Zhu W Q, Pan Y Z, Liu X, et al. Spatio-temporal distribution of net primary productivity along the northeast China transect and its response to climatic change. J Forestry Res, 2006, 17: 93-98
6 Holdridge L R. Life Zone Ecology. San Jose, Costa Rica: Tropical Science Center, 1967

7 Box E O. Plant functional types and climate at the global scale. J Veg Sci, 1996, 7: 309-320

8 Prentice I C, Cramer W, Harrison S P, et al. A global biome model based on plant physiology and dominance, soil properties and climate. J Biogeogr, 1992, 19: 117-134

9 Neilson R P. A model for predicting continental - scale vegetation distribution and water balance. Ecol Appl, 1995, 5: 362-385

10 Sellers P J, Bounoua L, Collatz G J, et al. Comparison of radiative and physiological effects of doubled atmospheric $\mathrm{CO}_{2}$ on climate. Science, 1996, 271: 1402-1406

11 Sitch S, Smith B, Prentice I C, et al. Evaluation of ecosystem dynamics, plant geography and terrestrial carbon cycling in the LPJ Dynamic Global Vegetation Model. Gl Change B, 2003, 9: 161-185

12 Lobo A, Rebollar J L G. Model-based discriminant analysis of Iberian potential vegetation and bio-climatic indices. Phys Ch P A, 2010, 35: $52-56$

13 Cosgrove B A, Barron E J, Pollard D. A simple interactive vegetation model coupled to the GENESIS GCM. Global Plan, 2002, 32: 253-278

14 Ren J Z, Hu Z Z, Zhao J, et al. A grassland classification system and its application in China. Rangeland J, 2008, 30: 199-209

15 Ren J Z. Grassland types in the central part of Gansu Province, China (in Chinese). J Gansu Agric Univ, 1959, 3: 1-15

$16 \mathrm{Hu}$ Z Z, Gao C X. Improvement of the comprehensive and sequential classification system of grasslands: I. Indices of grassland classes and index chart (in Chinese). Acta Pratac Sin, 1995, 3: 1-7

17 Ren J Z, Hu Z Z, Mu X D. Bio-climatic factors used to determine the first order of grassland classification in China (in Chinese). J Gansu Agric Univ, 1965, 1: 48-64

18 Ren J Z, Hu Z Z, Mu X D, et al. The comprehensive and sequential classification system of grassland and its significance of grassland genesis (in Chinese). Grassl China, 1980, 1: 12-24

19 Liang T G, Chen Q G, Ren J Z. Spatial distribution characteristics of grassland resource classes in Gansu Province. II. The electronic map of the comprehensive and sequential classification system of grassland based on GIS (in Chinese). J Lanzhou Univ, 2001, 37: 59-66

20 Hutchinson M F. Anusplin Version 4.3. Centre for Resource and Environmental Studies. Canberra: The Australian National University, 2004

21 Hijmans R J, Cameron S E, Parra J L, et al. Very high resolution interpolated climate surfaces for global land areas. Int J Clim, 2005, 25: 1965-1978

22 New M, Hulme M, Jones P. Representing twentieth-century spacetime climate variability. Part I: Development of a 1961-90 mean monthly terrestrial climatology. J Climate, 1999, 12: 829-856

23 New M, Lister D, Hulme M, et al. A high-resolution data set of surface climate over global land areas. Climate Res, 2002, 21: 1-25

24 Jarvis C H, Stuart N. A comparison among strategies for interpolating maximum and minimum daily air temperatures. Part II: The interaction between the number of guiding variables and the type of interpolation method. J Appl Met, 2001, 40: 1075-1084

25 Mitchell T D, Jones P D. An improved method of constructing a database of monthly climate observations and associated high-solution grids. Int J Clim, 2005, 25: 693-712

26 Holdridge L R. Determination of world plant formatons from simple climatic data. Science, 1947, 105: 367-368

27 Holdridge L R, Grenke W C, Hatheway W H, et al. Forest Environments in Tropical Life Zones: A Pilot Study. New York: Pergamon Press, 1971

28 Haxeltine A, Prentice C I. BIOME3: An equilibrium terrestrial biosphere model based on ecophysiological constraints, resource availability, and competition among plant functional types. Global Biog, 1996, 10: 693-709

29 Kaplan J O. Geophysical applications of vegetation modeling. Doctor Dissertation. Lund: Lund University, 2001

30 Kaplan J O. Wetlands at the last glacial maximum: Distribution and methane emissions. Geophys R L, 2002, 29: 1-3 
31 Kaplan J O, Bigelow N H, Prentice I C, et al. Climate change and arctic ecosystems: 2. Modeling, paleodata-model comparisons, and future projections. J Geophys Res, 2003, 108: 8171

32 Bigelow N H, Brubaker L B, Edwards M E, et al. Climate change and Arctic ecosystems: 1 . Vegetation changes north of $55^{\circ} \mathrm{N}$ between the last glacial maximum, mid-Holocene, and present. J Geophys Res, 2003, 108: 8170

33 Diffenbaugh N S, Sloan L C, Snyder M A, et al. Vegetation sensitivity to global anthropogenic carbon dioxide emissions in a topographically complex region. Global Biog, 2003, 17: 1067

34 Song M, Zhou C, Ouyang H. Simulated distribution of vegetation types in response to climate change on the Tibetan Plateau. J Veg Sci, 2005, 16: 341-350

35 Lugo A E, Brown S L, Dodson R, et al. The Holdridge life zones of the conterminous United States in relation to ecosystem mapping. J Biogeogr, 1999, 26: 1023-1038
36 IPCC. Climate Change 2001: The Scientific Basis. Cambridge: Cambridge University Press, 2001

37 IPCC. Climate Change 2007: The Scientific Basis. Cambridge: Cambridge University Press, 2007

38 Yue T X, Fan Z M, Liu J Y. Changes of major terrestrial ecosystems in China since 1960. Global Plan, 2005, 48: 287-302

39 Yue T X, Fan Z M, Liu J Y, et al. Scenarios of major terrestrial ecosystems in China. Ecol Model, 2006, 199: 363-376

40 Yue T X, Fan Z M, Chen C F, et al. Surface modelling of global terrestrial ecosystems under three climate change scenarios. Ecol Model, 2010, 222: 2342-2361

41 Zheng Y, Xie Z, Jiang L, et al. Changes in Holdridge Life Zone diversity in the Xinjiang Uygur Autonomous Region (XUAR) of China over the past 40 years. J Arid Env, 2006, 66: 113-126

42 Chen X, Zhang X S, Li B L. The possible response of life zones in China under global climate change. Global Plan, 2003, 38: 327-337

Open Access This article is distributed under the terms of the Creative Commons Attribution License which permits any use, distribution, and reproduction in any medium, provided the original author(s) and source are credited. 